\title{
The effect of type of sound damper material in the Helmholtz resonator to the output power spectrum of acoustic energy Harvester
}

\author{
Hedwigis Harindra ${ }^{1}$, Agung B. S. Utomo ${ }^{2}$, and Ikhsan Setiawan ${ }^{3}$ \\ ${ }^{1,2,3}$ Department of Physics, Faculty of Mathematics and Natural Sciences, Universitas Gadjah \\ Mada Sekip Utara BLS 21 Yogyakarta 55281 Indonesia \\ Email: ${ }^{1}$ hedwigis.harindra@mail.ugm.ac.id
}

Received 29 July 2019, Revised 28 August 2019, Published 30 September 2019

\begin{abstract}
Acoustic energy harvesting is one of many ways to harness acoustic noises as wasted energy into useful electical energy using an acoustic energy harvester. Acoustic energy harvester that tested by Dimastya (2018) which is consisted of loudspeaker and Helmholtz resonator, produced two-peak spectrum. It is suspected that the first peak is due to Helmholtz resonator resonance and the second peak comes from the resonance of the conversion loudspeaker. This research is to experimentally confirm the guess of the origin of the first peak. The experiments are performed by adding silencer materials on the resonator inner wall which are expected to be able to reduce the height of first peak and to know how they affect the output electric power spectrum of the acoustic energy harvester. Three different silencer materials are used, those are glasswool, acoustic foam, and styrofoam, with the same thickness of $12 \mathrm{~cm}$. The results show that glasswool absorbs sound more effectively than acostic foam and styrofoam. The use of glasswool, acoustic foam, and styrofoam with $12 \mathrm{~cm}$ thickness lowered the first peak by $90 \%$ (from $39 \mathrm{~mW}$ to $0,5 \mathrm{~mW}$ ), $82 \%$ (from $39 \mathrm{~mW}$ to $0,7 \mathrm{~mW}$ ), and $82 \%$ (from $39 \mathrm{~mW}$ to $0,7 \mathrm{~mW}$ ), respectively. Based on these results, it is concluded that the guess of the origin of the first peak is confirmed.
\end{abstract}

Keywords: the acoustic energy harvester, sound damper material, thickness, output electric power, spectrum peak frequency

\section{Introduction}

As time goes by, increasing human activity requires technologies that support and sophisticated. But whether we realize it or not, some of the human and technological activities cause noise. Noise causes various disturbances. In this regard, various efforts were made to reduce noise. Acoustic energy harvesting is one of many ways that utilizes noise as wasted energy into useful energy so that it can reduce noise (Fang et al., 2015).

An acoustic energy harvester utilizes noise to be converted into electrical energy. Noise, which includes acoustic energy, is converted to electrical energy and then stored in storage devices. The electricity can be used to supply electricity for low-power electronic devices (Pillai and Deenadayalan, 2014). Generally the acoustic energy 
harvester/device consists of three main components, namely acoustic resonator, acoustic transducer, and energy storage unit. The acoustic resonator used in an energy harvester can be either a Helmholtz resonator or a straight tube resonator. There are two types of straight tube resonators: open resonators (half wavelength resonators) and resonators with one closed end (quarter wavelength resonators) (Sohn and Park, 2011). There are three types of acoustic transducers (also called generators), namely electromagnetic generators, electrostatic generators, and piezoelectric generators (Hassan et al., 2014).

To test the amount of electrical power produced by the harvester, sound waves are generated from audio signals that are amplified by an audio amplifier and then forwarded to the loudspeaker. Some of the sound waves produced by the loudspeaker enter into the acoustic energy harvester. By this tool, the acoustic wave is converted to an electrical signal output in the form of voltage or alternating current that passes through the load resistor. From the potential difference between the two ends of the load resistor, the electric power generated can be calculated (Khan and Izhar, 2016, Khan and Izhar, 2018, Dimastya, 2018, Setiawan, 2019).

Various experiments have been carried out about the use of the Helmholtz resonator in an acoustic energy harvester. The Helmholtz resonator is widely used because of its ability to control low frequency noise compared to other resonators. Although there are various other ways to overcome the problem of low frequency noise, the stable and powerful performance of the Helmholtz resonator makes it one of the best choices in the noise control industry (Tang, 2005). In Helmholtz resonator, the mass of air in the neck acts the same as the mass system, while the air in the cavity acts the same as a spring system (Noh et al., 2013).

Dimastya (2018) tested the acoustic energy harvester using the Helmholtz resonator as an acoustic resonator and the conversion loudspeaker as an acoustic transducer. Resonators are made of wood with a wall thickness of $2 \mathrm{~cm}$ and a resonator cavity measuring $46 \mathrm{~cm} \times 46 \mathrm{~cm} \times 46 \mathrm{~cm}$. The resonator neck is made of pipe PVC with an inner diameter of $5.6 \mathrm{~cm}$ and a length of $2 \mathrm{~cm}, 10 \mathrm{~cm}$ and $20 \mathrm{~cm}$. Whether using a neck length of $2 \mathrm{~cm}, 10 \mathrm{~cm}$ or $20 \mathrm{~cm}$, the acoustic energy harvester has two operational sound frequency areas that produce relatively large electrical output power. The frequency area which first is around $41 \mathrm{~Hz}$ is thought to be related to the Helmholtz resonator resonance, while the second frequency region which is around $83 \mathrm{~Hz}$ is thought to be related to the resonance loudspeaker source used.

Based on these allegations, researchers are interested in conducting further studies of the frequency spectrum of the output produced by the acoustic energy harvester . To prove the truth of the allegation, researchers will use several types of sound dampening material mounted on the inner wall of the Helmholtz resonator. The use of sound dampening material is expected to eliminate or reduce the height of the peak of the electric resonance spectrum of the Helmholtz resonator. Helmholtz resonators with cavities coated with fibrous dampening material produce a resonant frequency which decreases with increasing thickness of the fibrous dampening material (Selamet et al., 2005). As with the classic Helmholtz resonator, the deeper the cavity resonator, the lower the resonant frequency (Gourdon et al., 2017). In addition, each type of sound 
dampening is also used to determine its effect on the two peaks of the output electric power spectrum produced by the acoustic energy harvester. Sound absorbers that will be used in this study are acoustic foam, glasswool, and styrofoam with a thickness of 12 $\mathrm{cm}$. Therefore, in this study anwas studied experiment the effect of sound dampening in the Helmholtz resonator on the spectrum of the electric power output produced by an acoustic energy harvester.

\section{Research Methods}

\subsection{Selection of Electrical Load Resistance}

Experiments in the selection of electrical load resistance was carried out so that by using selected load resistance $\left(\boldsymbol{R}_{\boldsymbol{b}}\right)$ which produced maximum rms power used electricity output $\left(\boldsymbol{P}_{\boldsymbol{r m s}}\right)$ when testing this harvester in this research. On the back of a Helmholtz resonator attached 1 (one) 8 inches-diameter Concept subwoofer conversion loudspeaker models CW-8 with a resistance coil $\left(\boldsymbol{R}_{\boldsymbol{l k}}\right)$ that parallelly connected with the

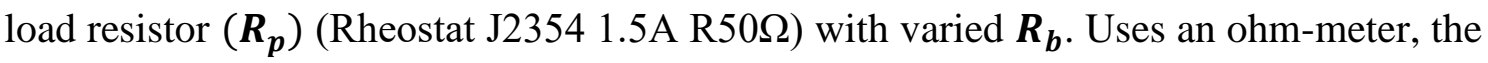
measureable resistance is parallel resistance $\left(\boldsymbol{R}_{\boldsymbol{p}}\right)$ number of the two resistances. The magnitude of the load resistor resistance is calculated using the equation

$$
\boldsymbol{R}_{b}=\frac{\boldsymbol{R}_{p} \boldsymbol{R}_{l k}}{\boldsymbol{R}_{l k}-\boldsymbol{R}_{p}}
$$

Experiment by generating audio signals and set the frequency at any frequency using the GW-Instek Audio Function Generator (AFG) models GFG-8250A. The sound pressure level (SPL) is fixed at $90 \mathrm{~dB}$ by using a unit of audio amplifier and monitoring it using an digital SPL-Lutron model SL-40. The sound waves received by the conversion loudspeaker are converted into alternating electric current by the loudspeaker and then pass through the load resistor. The rms (root mean square) potential difference $\left(\boldsymbol{V}_{\boldsymbol{r m s}}\right)$ between the two ends of load resistor is measured using a Sanwa digital voltmeter model RD700. The rms electrical output power $\left(\boldsymbol{P}_{\boldsymbol{r m s}}\right)$ is measured using the equation

$$
\boldsymbol{P}_{r m s}=\frac{\boldsymbol{V}_{r m s}^{2}}{\boldsymbol{R}_{b}}
$$

Experiments with measuring $\boldsymbol{V}_{\boldsymbol{r} m \boldsymbol{s}}$ mentioned above were carried out for various values parallel resistance from $0 \Omega$ to $\mathrm{V}_{\mathrm{rms}} 3.2 \Omega$ of increase every $0.1 \Omega$. Load resistors that can produce the greatest output power will be used in further experiments.

\subsection{Testing of Acoustic Energy Harvester without Sound Damper in Helmholtz Resonators}

The schematic arrangement of experimental equipment without sound damper material is shown in Figure 1. A full range source loudspeaker that is used as a sound source is 1 piece with a nominal diameter of 15 inches and is mounted on a box measuring $45.5 \mathrm{~cm} \times 30 \mathrm{~cm} \times 65 \mathrm{~cm}$. Audio signals are generated and their frequency is adjusted at any frequency using AFG. The audio signal is amplified by an audio 
amplifier. To measure the sound pressure level (SPL) of sound waves produced by the source loudspeaker, used a SPL-meter which is refuted using a stative and holder. This is placed at a distance of $20 \mathrm{~cm}$ from the Helmholtz resonator.
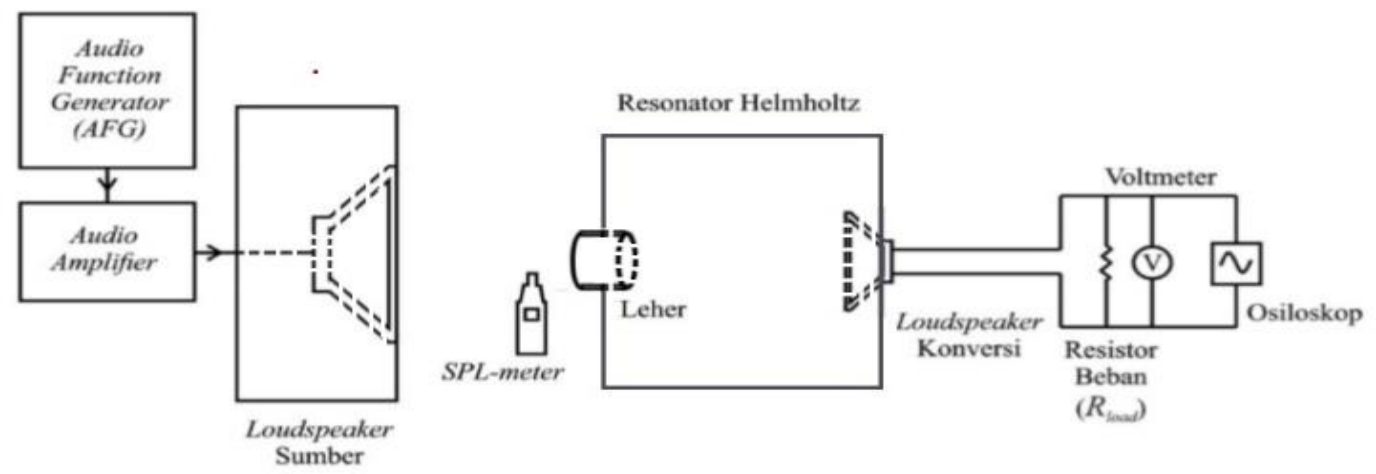

Figure 1.Schematic arrangement of experimental equipment without sound absorbing material

The incoming sound waves are collected and amplified by the Helmholtz resonator. The incoming sound wave is converted into alternating electric current by a conversion loudspeaker and then passes through the load resistor. The load resistor resistance used is the resistance $R_{b}$ that has been selected in the previous experiment. The rms potential difference in between the two ends of the load resistor is measured and then the electrical power rms output produced by this acoustic energy harvester can be calculated using equation (2).

Experiments by measuring $V_{r m s}$ mentioned above were carried out for various sound frequencies from $20 \mathrm{~Hz}$ to $200 \mathrm{~Hz}$ with an increase every $1 \mathrm{~Hz}$.

\subsection{Sound Damper Materials Procurement and Installation}

This research was carried out in laboratory experiments using three types of sound dampening materials as shown in Figure 2, namely glasswool, acoustic foam, and styofoam. The damper material is cut adjusting the size of the Helmholtz resonator wall. Each damper material is mounted stacked on the inner wall of the Helmholtz resonator cavity until it reaches a thickness of $12 \mathrm{~cm}$.

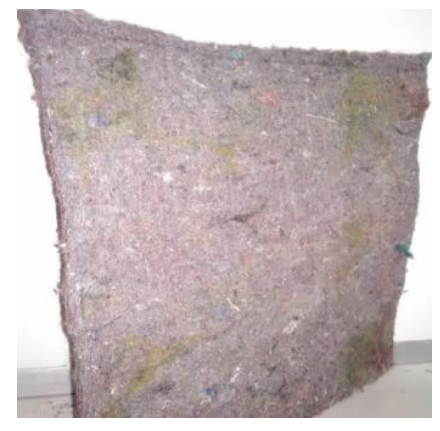

(a)

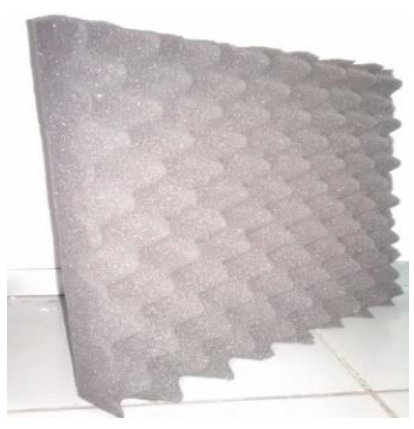

(b)

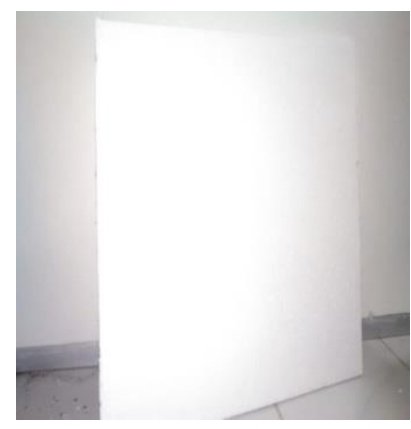

(c)

Figure 2.Sound damper material that has been cut: (a) glasswool, (b) acoustic foam, and (c) styrofoam 
In this study the damper material is the main component to determine the effect of its use in the resonator Helmholtz. The damper material has been measured and cut according to the length, width, and thickness that had been calculated previously by the researcher. Damper material ready to be installed on each side of the Helmholtz resonator equipped with loudspeaker a type conversion subwoofer. The damper material that has been installed on the Helmholtz resonator is shown by Figure 3 .

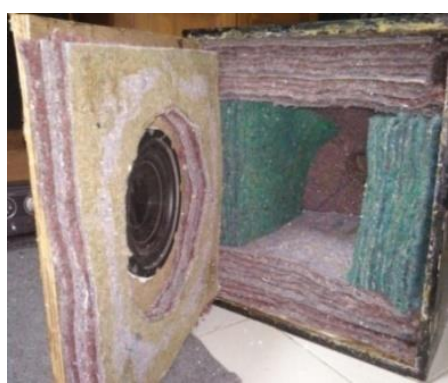

(a)

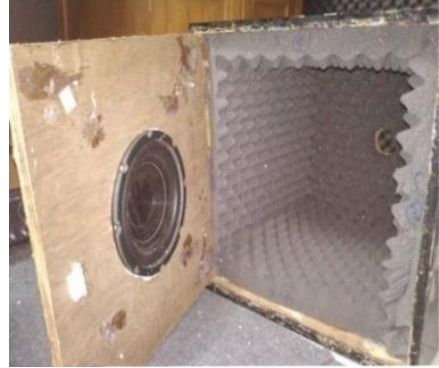

(b)

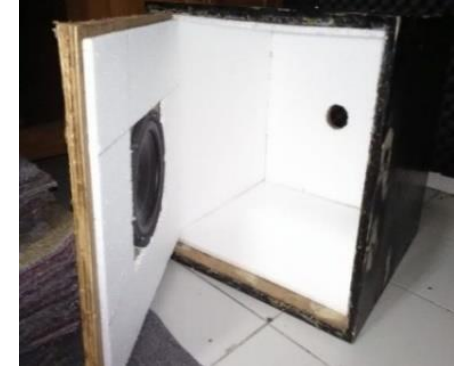

(c)

Figure 3.The sound damper material that has been installed on the Helmholtz resonator: (a) glasswool, (b) acoustic foam, and (c) styrofoam

\subsection{Testing of Electric Energy Harvester Testing of Acoustic Energy Harvester With Sound Dampers in Helmholtz Resonators}

The schematic arrangement of the experimental equipment with sound damper material is shown in Figure 4. The working steps of the acoustic energy harvester testing experiment using the sound damper are the same as the energy harvester testing experiments acoustics without using sound damper.
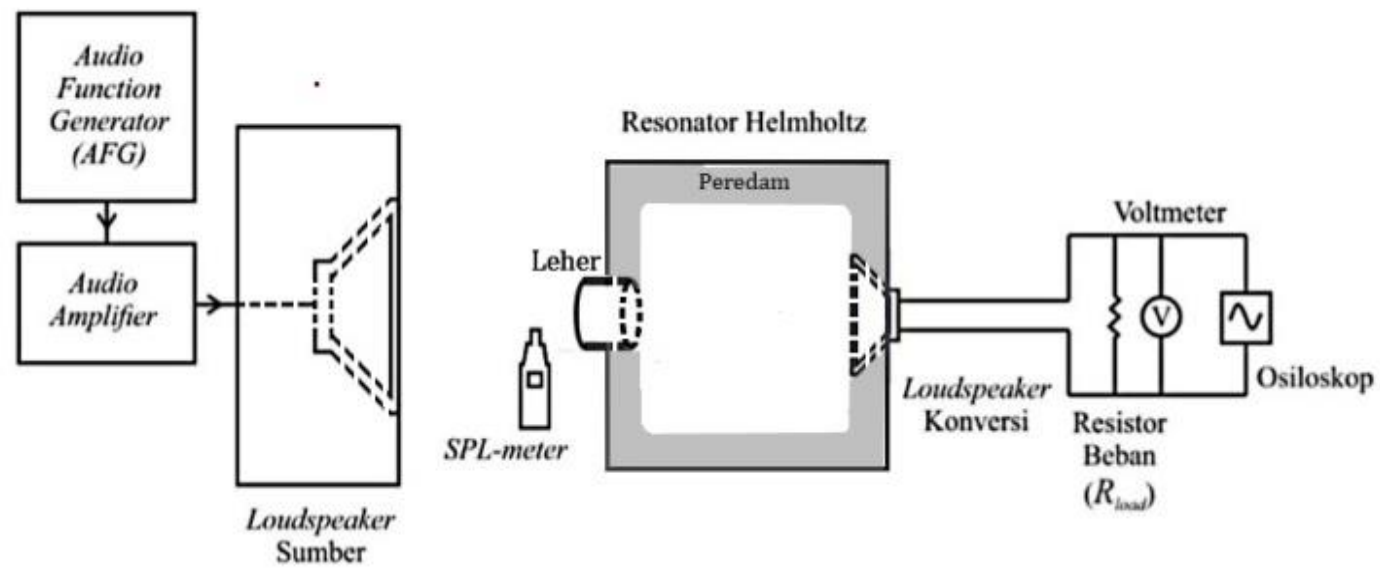

Figure 4.Schematic arrangement of experimental equipment using sound dampening material

Using the same load resistance and sound frequencies from $20 \mathrm{~Hz}$ to $200 \mathrm{~Hz}$ with an increase every $1 \mathrm{~Hz}$, the rms potential difference between the two ends of the load resistor is measured and the rms electrical power output produced by this acoustic energy harvester is calculated using equation (2). 


\section{Results And Discussion}

\subsection{Load Resistance Used}

To determine which load resistance is used, a graph is made of the relationship between the output electrical power $\left(P_{r m s}\right)$ and the load resistor $\left(R_{b}\right)$ to see how much electrical resistance produces the largest output power. The used load resistors and conversion loudspeaker have a resistance range of $0 \Omega-50 \Omega$ and $4 \Omega$, while the parallel resistance range is $0.6 \Omega-3.2 \Omega$.

The results of large measurements of load resistance using a subwoofer conversion loudspeaker on the Helmholtz resonator without a damper are subjected to sound waves with a SPL of fixed $90 \mathrm{~dB}$ at any fixed frequency of $57 \mathrm{~Hz}$ shown in Figure 5.

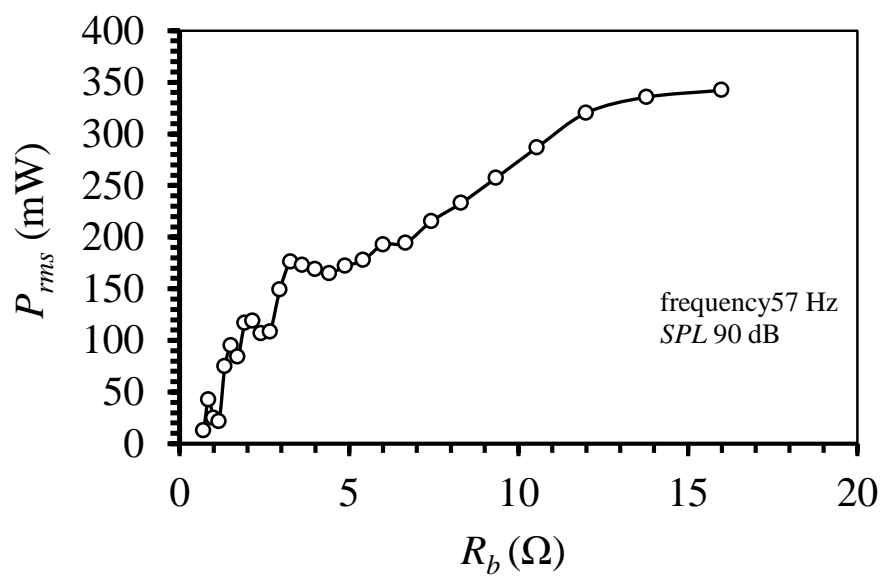

Figure 5.The relationship graph of electrical power output produced by acoustic energy harvesters and load resistors at any fixed frequency of $57 \mathrm{~Hz}$ and fixed SPL of $90 \mathrm{~dB}$

Based on Figure 5, the results of the measurement of electric power output for the variation of the load resistor resistance in the range of $0.7 \Omega-16 \Omega$ tends to rise exponentially in line with the large increase in load resistor resistance. It appears that this acoustic energy harvester generates the largest output power of $342 \mathrm{~mW}$ at $16 \Omega$ load resistance. Thus, at the next experimental stage the load resistance of 16 digunakan is used.

\subsection{Testing of Acoustic Energy Harvester Without Using and Using Sound Dampers in Helmholtz Resonators}

Electric power generated when without using and using sound dampers with a thickness of $12 \mathrm{~cm}$ is explained as follows.

\subsubsection{Glasswool}


The results of measurements of rms electrical power output from acoustic energy harvester without sound damper and with glasswool sound damper as thick as $12 \mathrm{~cm}$ in the Helmholtz resonator are subjected to sound waves in the frequency range of $20 \mathrm{~Hz}$ $200 \mathrm{~Hz}$ and SPL $90 \mathrm{~dB}$ are presented in Figure 6. Based on Figure 6, both when not given and after being given a glasswool sound damper as thick as $12 \mathrm{~cm}$ this acoustic energy harvester has two operational areas. The operational area is the frequency region that produces the maximum rms power output (Dimastya, 2018).

In the spectrum when without using sound damper, the first operational area is in the frequency range of $23 \mathrm{~Hz}-36 \mathrm{~Hz}$ and the second operational area is in the $46 \mathrm{~Hz}-102$ $\mathrm{Hz}$ frequency range. In the first operational area, the peak of the spectrum is at a frequency of $29 \mathrm{~Hz}$ which produces an rms electrical power output of $3.9 \mathrm{~mW}$, whereas in the second operational area, the peak of the spectrum is at a frequency of $56 \mathrm{~Hz}$ which produces an rms electrical power output of $4.6 \mathrm{~mW}$.

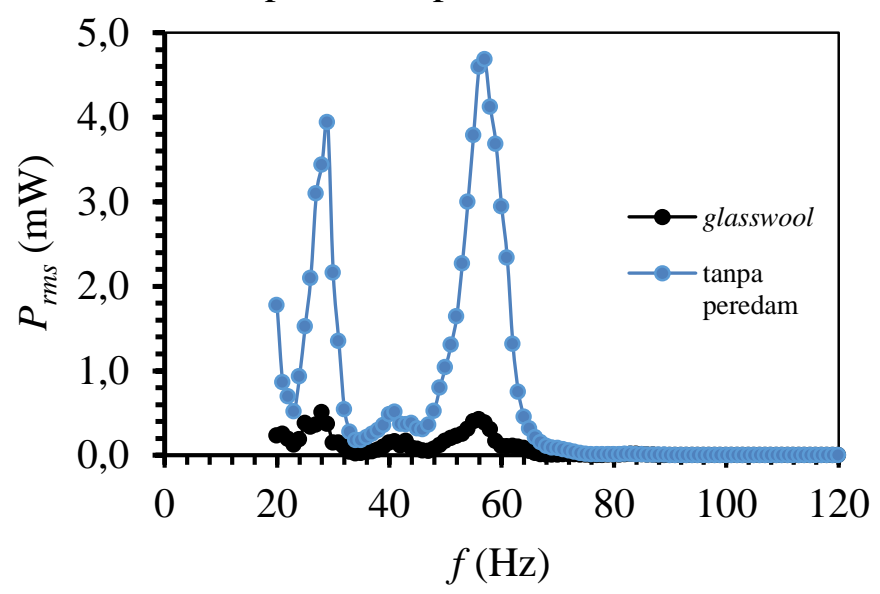

Figure 6. Graphic relationship of rms electrical power output produced by acoustic energy harvester with $12 \mathrm{~cm}$-glasswool sound damper in Helmholtz resonators and the sound wave frequency with which the fixed SPL at $90 \mathrm{~dB}$

In the spectrum when using glasswool, the first operational area is in the frequency range of $23 \mathrm{~Hz}-35 \mathrm{~Hz}$ and the second operational area is in the $47 \mathrm{~Hz}-106 \mathrm{~Hz}$ frequency range. In the first operational area, the peak of the spectrum is at a frequency of $28 \mathrm{~Hz}$ which produces a rms electrical power output of $0.5 \mathrm{~mW}$, whereas in the second operational area, the peak of the spectrum is at a frequency of $56 \mathrm{~Hz}$ which produces a rms electrical power output of $0.4 \mathrm{~mW}$. The difference in spectrum heights when without using and using glasswool sound dampers shows that glasswool can reduce sound up to $90 \%$ both at the peak of the first spectrum $(3.9 \mathrm{~mW}$ to $0.4 \mathrm{~mW})$ and the second peak of the spectrum $(4.6 \mathrm{~mW}$ to $0.4 \mathrm{~mW})$ compared when without using sound damper so that the spectrum height can be reduced.

\subsubsection{Acoustic foam}

The results of measurements of rms electric power output from an acoustic energy harvester with $12 \mathrm{~cm}$ thick-acoustic foam sound damper in a Helmholtz resonator subject to sound waves in the frequency range of $20 \mathrm{~Hz}-200 \mathrm{~Hz}$ and SPL of $90 \mathrm{~dB}$ are presented in Figure 7. 
Based on the Figure 7, a decrease in the peak height of the spectrum again after being given acoustic foam. When using acoustic foam, the first operational area is in the frequency range of $23 \mathrm{~Hz}-35 \mathrm{~Hz}$ with the peak being at a frequency that produces rms electrical power output of $0.7 \mathrm{~mW}$. The second operational area is in the frequency range of $47 \mathrm{~Hz}-107 \mathrm{~Hz}$ with the peak being at a frequency that produces rms electrical power output of $0.5 \mathrm{~mW}$. When compared to without using a damper, this acoustic foam can reduce the height of the peak of the spectrum by reducing the sound up to $82 \%$ at the peak of the first spectrum $(3.9 \mathrm{~mW}$ to $0.7 \mathrm{~mW})$ and $89 \%$ at the peak of the second spectrum ( $4.6 \mathrm{~mW}$ to $0.5 \mathrm{~mW})$.

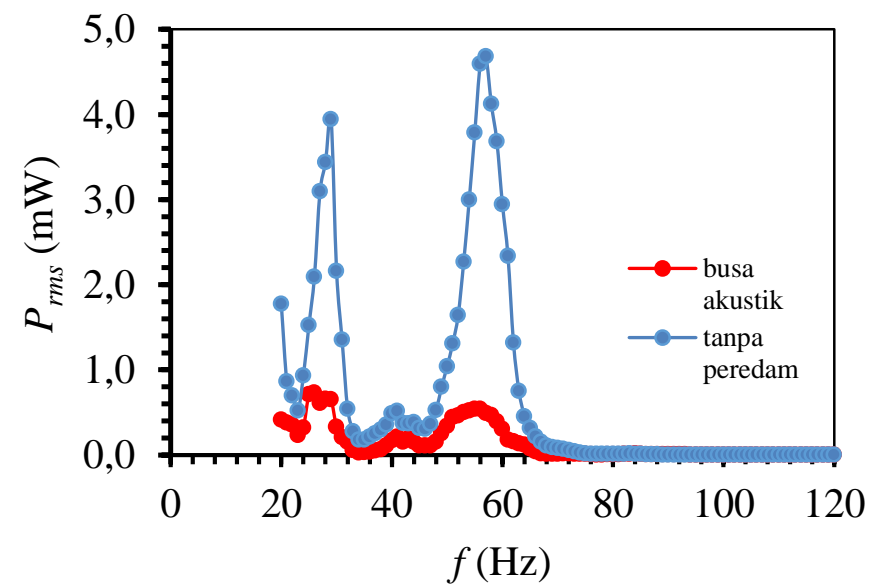

Figure 7. Graphic relationship of rms electrical power output produced by acoustic energy harvester with $12 \mathrm{~cm}$ thick-acoustic foam sound damper in the Helmholtz resonator and the frequency of the sound waves about it with fixed SPL of $90 \mathrm{~dB}$

\subsubsection{Styrofoam}

Measuring rms electrical power output output from an acoustic energy harvester with $12 \mathrm{~cm}$ thick-styrofoam sound damper in the Helmholtz resonator that is subjected to sound waves in the range frequencies of $20 \mathrm{~Hz}-200 \mathrm{~Hz}$ and SPL are $90 \mathrm{~dB}$ presented in Figure 8. 


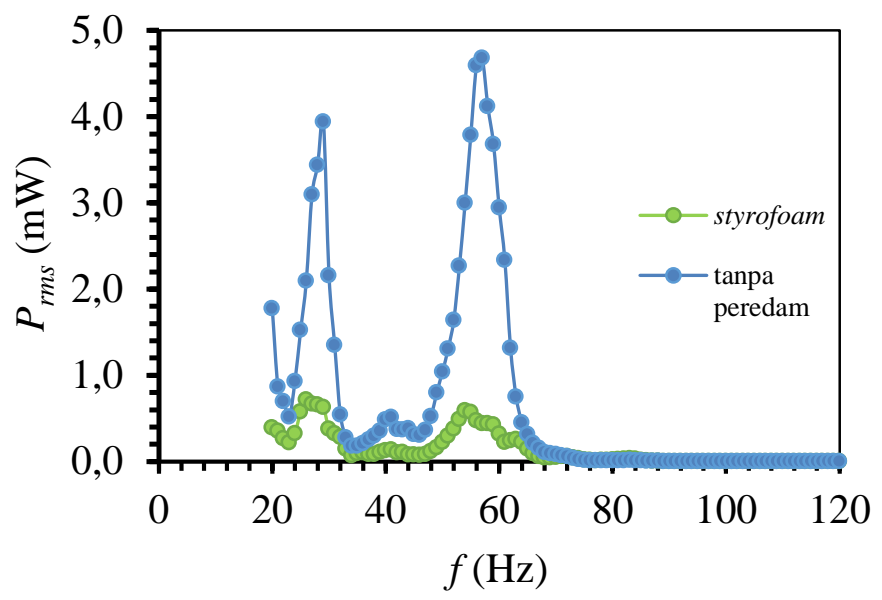

Figure 8. Graphic relationship between the rms output electrical power of acoustic energy harvester with $12 \mathrm{~cm}$-styrofoam sound damper in the Helmholtz resonator and the frequency of a sound wave about it with fixed SPL of $90 \mathrm{~dB}$

Based on Figure 8, after using styrofoam sound damper the peak height of the spectrum again decreases compared to when without the use of sound damper. When using styrofoam, the first operational area is in the frequency range of $23 \mathrm{~Hz}-35 \mathrm{~Hz}$ and the second operational area is in the $46 \mathrm{~Hz}-109 \mathrm{~Hz}$ frequency range. In the first operational area, the peak of the spectrum is at a frequency of $26 \mathrm{~Hz}$ which produces rms electrical power output of $0.7 \mathrm{~mW}$, whereas in the second operational area, the peak of the spectrum is at a frequency of $55 \mathrm{~Hz}$ which produces rms electrical power output of $0.6 \mathrm{~mW}$. There is a difference in the height of the spectrum when without using and using styrofoam. This shows that styrofoam can reduce sound up to $82 \%$ both at the peak of the first spectrum ( $3.9 \mathrm{~mW}$ to $0.7 \mathrm{~mW}$ ) and $86 \%$ at the peak of the second spectrum $(4.6 \mathrm{~mW}$ to $0.6 \mathrm{~mW}$ ) compared to without use sound damper so that the spectrum height can be reduced.

\subsubsection{The effect of the sound dampening type with a thickness of $12 \mathrm{~cm}$}

The rms electrical power output produced by the glasswool, acoustic foam, and styrofoam sound damper at a thickness of $12 \mathrm{~cm}$ with the peak frequency of the first and second spectrums put together in one graph shown in Figure 9.

From these graphs, there is a difference that was not significant (relatively constant) relating to the location of the frequency the peak of the spectrum of the Helmholtz resonator that is given a glasswool, acoustic foam, and styrofoam sound damper with a thickness of $12 \mathrm{~cm}$, but there are differences in the location of the frequency of the peak of the first spectrum at Helmholtz resonator that is given sound damper with acoustic foam and styrofoam. This is due to the acoustic stiffness of the sound waves that are trapped inside the resonator cavity. The volume of the resonator cavity decreases when given a sound damper with increased thickness, causing a shift in the peak frequency of the spectrum. 


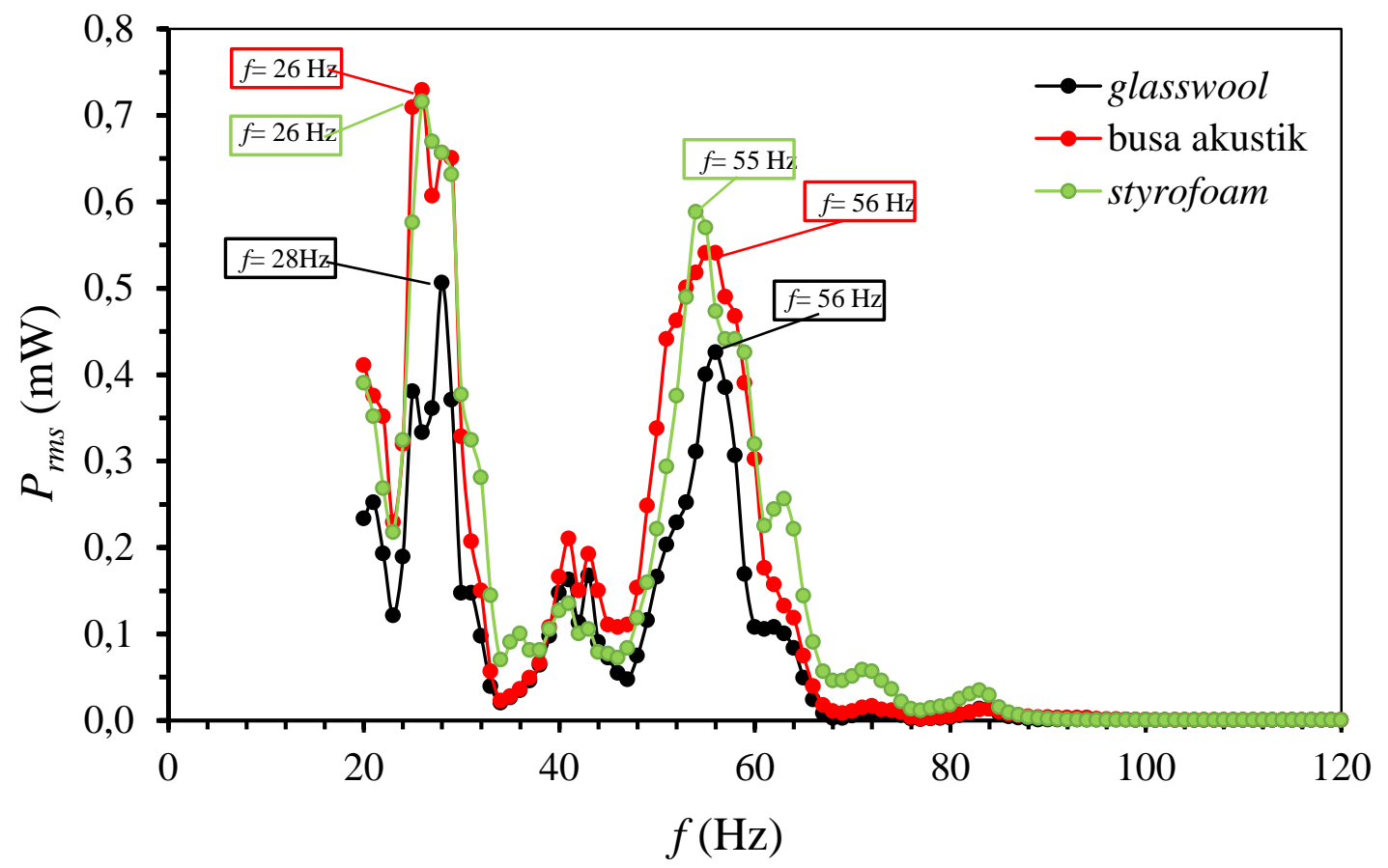

Figure 9.Graph relation of rms output power generated by acoustic energy harvester and sound frequencies about it for some types of sound damper with a thickness of 12 $\mathrm{cm}$ in the Helmholtz resonators

In Figure 10, there is a considerable difference in the rms electrical power output between the Helmholtz resonator which is not given and is given a sound damper. The results show that glasswool sound damper are quite effective in sound muffling so that they can reduce the height of the peak of the spectrum compared to acoustic foam and styrofoam. The first peak of the spectrum which decreases in height shows that the allegations studied proved correct that the peak of the first spectrum was related to the resonance of the Helmholtz resonator. Because it is quite effective in muffling the sound, the rms electric power output produced is lower than before it was given a sound damper. 


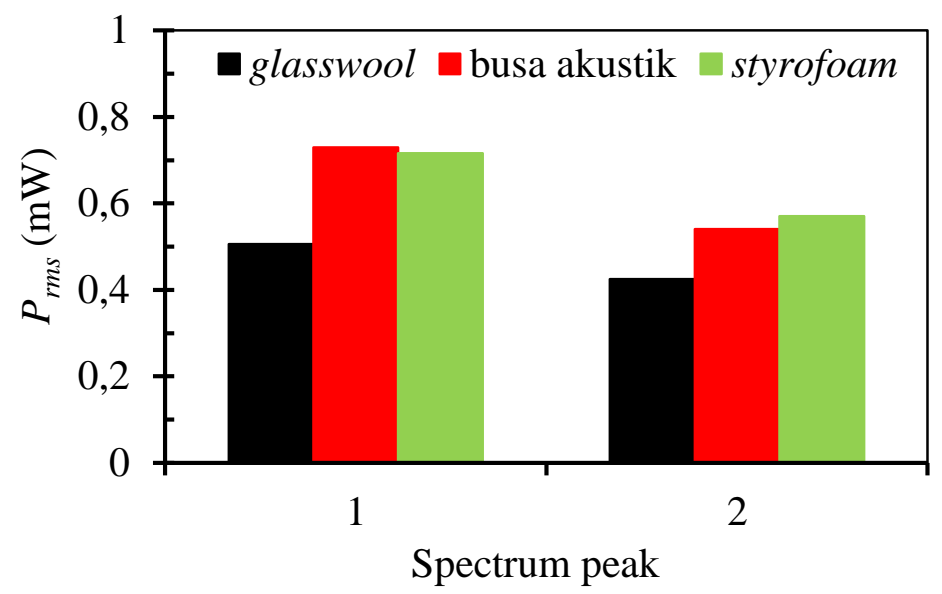

Figure 10. Graph of rms electrical power output produced by acoustic energy harvester at the first and second spectrum peaks for several types of sound damper with thickness $12 \mathrm{~cm}$ inside the Helmholtz resonator

\section{Conclusion}

Experimental results obtained in this study show that glasswool, acoustic foam and styrofoam sound damper can reduce the peak height of the Helmholtz resonator resonant spectrum, but of the three sound damper which are more effective at absorbing sound is glasswool, noise suppression glasswool can reduce the height of the peak of the spectrum up to $90 \%$ with the rms electric power output generated of $0.5 \mathrm{~mW}$. With the decrease in the peak height of the spectrum it is alleged that the first spectral peaks associated with the Helmholtz resonator resonance proved to be correct.

\section{Suggestions}

After conducting research the researcher can provides suggestion for further research is to use the Helmholtz resonator size variation used. With the variation in the size of the resonator, it can also be seen how it affects the rms output power spectrum produced by the acoustic energy harvester.

\section{References}

R. A. Dimastya, "Pembuatan dan Pengujian Alat Pemanen Energi Akustik (Acoustic Energy Harvester) Menggunakan Loudspeaker dan Resonator Helmholtz Sebagai Sumber Energi Alternatif," Skripsi, Fakultas Matematika dan Pengetahuan Alam, Universitas Gadjah Mada, 2018.

L. H. Fang, S. I. S. Hassan, R. B. A. Rahim, and J. M. Nordin, "A Review of Techniques Design Acoustic Energy Harvesting," IEEE SCOReD, pp. 37-42, 2015.

E. Gourdon, M. E. Mankibi, R. Issoglio, P. Stabat, D. Marchio, and C. F. Dordelly, "Silencer Design for Awning Windows: Modified Helmholtz Resonators with Perforated Foam," Build. Simul., vol. 10, no. 5, pp. 677-685, 2017.

H. F. Hassan, S. I. S. Hassan, and R. A. Rahim, “Acoustic Energy Harvesting Using 
Piezoelectric Generator for Low Frequency Sound Waves Energy Conversion," Intern. J. Eng. Tech, vol. 5, no. 6, pp. 4702-4707, 2014.

F. U. Khan and Izhar, "An Improved Design of Helmholtz Resonator for Acoustic Energy Harvesting Devices," IEEE, pp. 238-288, 2016.

F. U. Khan and Izhar, "Three Degree of Freedom Acoustic Energy Harvester Using Improved Helmholtz Resonator," Intern. J. Prec. Eng. Manufact., vol. 19, no. 1, pp. 143-154, 2018.

S. Noh, H. Lee, and B. Choi, "A Study on the Acoustic Energy Harvesting with Helmholtz Resonator and Piezoelectric Cantilevers," Intern. J. Prec. Eng. Manufact., vol. 14, no. 9, pp. 1629-1635, 2013.

M. A. Pillai and E. Deenadayalan, "A Review of Acoustic Energy Harvesting," Intern. J. Prec. Eng. Manufact., vol. 15, no. 5, pp. 949-965, 2014.

A. Selamet, M. B. Xu, I. J. Lee, and N. T. Huff, "Helmholtz Resonator Lined with Absorbing Material," J. Acoust. Soc. Am., vol. 117, no. 2, pp. 725-733, 2005.

I. Setiawan, "Studi Eksperimental Penggunaan Loudspeaker Sebagai Pengkonversi Energi Bunyi Menjadi Listrik Dalam Alat Pemanen Energi Akustik (Acoustic Energy Harvester)," Jurnal Teknologi, vol. 11, no. 1, pp. 9-16, 2019.

C. H. Sohn and J. H. Park, "A comparative study on acoustic damping induced by halfwave, quarter-wave, and Helmholtz resonators," J. Aerosp. Sci. Tech., vol. 15, no. 8, pp. 606-614, 2011.

S. Tang, "On Helmholtz Resonators with Tapered Necks," J. Sound Vib., vol. 279, no. 3-5, pp. 1085-1096, 2005. 